\title{
Protective role of turmeric on histological, ultrastructural and sero- biochemical changes in cisplatin-induced nephrotoxicity in female rats
}

\author{
B. Ramya, Y. Anjaneyulu, A. Gopala Reddy ${ }^{1}$, D. Madhuri, M. Lakshman and P. Shivakumar ${ }^{1}$
}

\begin{abstract}
Department of Veterinary Pathology, College of Veterinary Science, Sri Venkateswara Veterinary University, Rajendranagar, Hyderabad, Andhra Pradesh, India; 1. Department of Vetinary Pharmacology \& Toxicology, College of Veterinary Science, Sri Venkateswara Veterinary University, Rajendranagar, Hyderabad, Andhra Pradesh, India

Corresponding author: P. Shivakumar, e mail: drshiva40@gmail.com
\end{abstract}

Received: 27-06-2013, Revised: 24-08-2013, Accepted: 26-08-2013, Published online: 05-10-2013

doi: 10.14202/vetworld.2013.865-869 How to cite this article: Ramya B, Anjaneyulu Y, Gopala Reddy A, Madhuri D, Lakshman M and Shivakumar P (2013) Protective role of turmeric on histological, ultrastructural and sero-biochemical changes in cisplatin-induced nephrotoxicity in female rats, Veterinary World 6(11): 865-869.

\begin{abstract}
Aim: Protective role of turmeric was assessed against cisplatin-induced histological and ultra-structural changes in kidney.

Materials and Methods: A total of 48 rats were divided into 4 groups of 12 rats in each. Group 1 was kept as sham control, group 2 was treated with cisplatin (@ $2 \mathrm{mg} / \mathrm{kg}$ b.wt, intraperitoneally on day 1, 7, 14 and 21), group 3 with turmeric (@ 0.05 $\mathrm{mg} / \mathrm{kg}$ b.wt. p.o. once daily for 28 days) and group 4 with cisplatin + turmeric (as per above schedule). Blood was collected at fortnight intervals and serum was separated for estimation of kidney biomarkers. Six rats in each group were then euthanized on day 14 and 28 for histopathology, and tissue parameters were assayed on day 28.
\end{abstract}

Results: Thibarbituric acid reacting substances (TBARS), protein carbonyls, serum creatinine, blood urea nitrogen (BUN) were significantly $(\mathrm{P}<0.05)$ increased, while GSH was significantly $(\mathrm{P}<0.05)$ decreased in group 2 as compared to other groups. Histological sections of kidney from group 2 rats showed marked inter-tubular haemorrhages, congestion, marked dilation of tubules, and other lesions of pathological significance. Ultrastructural changes of pathological significance were also recorded in group 2. Kidney sections of group 4 showed nucleus with uniform size with well differentiated nuclear membrane and nucleolus, and prominent inter tubular and inter cellular junctions.

Conclusion: The study revealed that cisplatin induces nephrotoxicity due to oxidative stress and turmeric was found beneficial in countering the adverse effects.

Key words: cisplatin, nephrototoxicity, oxidative stress, turmeric.

\section{Introduction}

Cancer occurance in India is estimated to be around 2.5 million with over eight lakh new cases and 50 thousand deaths occurring each year [1]. Chemotherapy and radiotherapy are the most common modalities of cancer treatment. Cisplatin is a platinum containing drug used in the treatment of various types of cancers [2]. Cisplatin based combination chemotherapy regimens are currently used as front line therapy in treatment of various solid tumors [3]. It has dose-dependent cytotoxicity on kidney and other organs $[4,5]$. The adverse drug reactions were due to the increased production of reactive oxygen species leading to oxidative stress [6]. Nephroprotective action of Merremia emarginata in cisplatin toxicity was reported by Sudhavani et al. [7]. Ulkanet al. [8] reported protective role of melatonin, potent anioxidant in cisplatin induced nephrotoxicity. Various herbs rich in flavonoids and polyphenols have antioxidant properties [9]. Amongst the alternative systems of medicine, the use of herbal medicine has attracted wide attention in India, in view of the availability of medicinal plants in abundance and their easy accessibility. The rhizome of Curcuma longa is

Copyright: The authors. This article is an open access article licensed under the terms of the Creative Commons Attribution License (http://creativecommons.org/licenses/by/2.0) which permits unrestricted use, distribution and reproduction in any medium, provided the work is properly cited. the most useful part of the plant for culinary and medicinal purposes. Turmeric is obtained from dried rhizomes of $C$. longa. Biological properties of turmeric includes antibacterial, antiprotozoan, antiviral, hypolipemic, hypoglycemic, anticoagulant, antioxidant, antitumour and anticarcinogenic activities [10]. Turmeric has protective role in cisplatin induced hepato-toxicity [11].

The present study was undertaken in female Sprague dawley rats to evaluate the effect of cisplatin on kidney biomarkers and histological, ultrastrucural alterations, if any, and to assess the protective role of turmeric in ameliorating the toxic effects.

\section{Materials and Methods}

Ethical approval: The protocol of the experiment was approved by the Institutional Animal Ethics Committee according to guidelines given by Committee for the Purpose of Control and Supervision of Experiments on Animals (CPCSEA).

Chemical Reagents: Cisplatin was obtained from VHB Life Sciences Ltd.,Mumbai. Fresh turmeric was procured from farm and was shade dried and made into powder. Other chemicals and reagents were obtained from Qualigens Pvt. Ltd., Mumbai, India.

Animals: Female rats of Sprague dawley (Rattusnorvegicus) strain 3 months old (weighing 150-200g) were procured from NCLAS- NIN, Tarnaka, Andhra Pradesh. 
Experimental procedure: A total of 48 Sprague dawley female rats were randomly divided into 4 groups consisting of 12 rats in each group. All the groups were maintained as per the following treatment schedule. Group 1, Sham control were given saline by intraperitoneal injection weekly once for 4 weeks, group 2, Cisplatin control (Cisplatin@ 2 mg / kg body wt. by i.p injection weekly once for 4 weeks), group 3, turmeric control (turmeric @ 0.05 ppm by oral gavage needle daily) and group 4 Cisplatin +turmeric (Cisplatin@ $2 \mathrm{mg} / \mathrm{kg}$ body wt. by intraperitoneal injection weekly once for 4 weeks + turmeric @ 0.05 ppm body wt. by oral gavage needle daily). Turmeric was administered by dissolving in DMSO.

Statistical analysis: The data were subjected to statistical analysis by applying one way ANOVA. Differences between means tested using Duncan's multiple comparison tests and significance was set at $\mathrm{P}$ $<0.05$ [12].

Blood was collected by retro orbital plexus at fortnight intervals and serum was separated for estimation of renal biomarkers [13]. Six rats in each group were euthanized on day 14 and 28 for histopathology, while tissue parameters were assayed on day 28. The tissue pieces were stored in $10 \%$ NBFfor histopathological study. The fixed tissues were processed and stained with Haematoxylin and Eosin $(\mathrm{H}$ \& E) [14] stain for histopathology. To study ultra structural changes, samples were collected in vials and fixed in $2.5 \%$ gluteraldehyde in $0.05 \mathrm{M}$ phosphate buffer ( $\mathrm{pH} 7.2$ ) for $24 \mathrm{~h}$ at $4^{\circ} \mathrm{C}$, after the post-fixation, samples were dehydrated in a series of graded alcohol and infiltrated and embedded in Araldite 6005 resin. Ultra thin sections (50-70 nm thickness) were cut with a glass knife on a Leica Ultra cut UCT-GA-D/E-1/00 ultra microtome and mounted on grids. Then the sections were stained with saturated aqueous uranyl acetate and counter stained with $4 \%$ lead citrate and were observed at various magnifications under a transmission electron microscope (Model: Hitachi, H7500) at RUSKA Lab, College of Veterinary Science, Hyderabad, India.[15].

After sacrifice, kidneys were immediately excised, rinsed with ice-cold normal saline and stored at $-50^{\circ} \mathrm{C}$ for further homogenization to estimate thiobarbituric acid reacting substances (TBARS), protein carbonyls and reduced glutathione (GSH).

Measurement of glutathione (GSH): Kidney GSH levels were measured as per the procedure described by[16]. $100 \mu \mathrm{l}$ of $25 \%$ TCA was added to $400 \mu \mathrm{l}$ of kidney homogenate, centrifuged and supernatant is collected to use as sample. To $2.0 \mathrm{ml}$ of $0.6 \mathrm{mM} \mathrm{5-5'}$ dithiobis-2-nitrobenzoic acid (DTNB) in $0.2 \mathrm{M}$ sodium phosphate (pH 8), $0.1 \mathrm{ml}$ of sample and $0.9 \mathrm{ml}$ of $0.2 \mathrm{M}$ phosphate buffer was added and the absorbance was read at $412 \mathrm{~nm}$ against a reagent blank. The standards $(0.05-5 \mathrm{mg} / \mathrm{ml})$ were also treated in the same way.
Measurement of Thiobarbituric acid reacting substances (TBARS): Kidney TBARS levels were measured as per the procedure described by[17]. $500 \mu \mathrm{l}$ of supernatant from the homogenate, $1 \mathrm{ml}$ of $10 \%$ TCA and $1 \mathrm{ml}$ of $0.67 \%$ thiobarbituric acid were taken in a tightly Stoppard glass tube. The tube was kept in hot water bath maintained at $100^{\circ} \mathrm{C}$ for 45 minutes. Remove the tube from water bath and the contents are centrifuged after cooling. The supernatant was collected and read the absorbance at $532 \mathrm{~nm}$ against blank. The concentration of test samples was obtained using molar extinction coefficient of MDA.

Measurement of protein carbonyls: Kidney protein carbonyl levels were measured as per the procedure described by[18]. $1 \mathrm{ml}$ of homogenate containing $1 \mathrm{mg}$ protein was added to $4 \mathrm{ml}$ of $10 \mathrm{mMdinitrophenyl}$ hydrazine (DNPH) in $2.5 \mathrm{M} \mathrm{HCl}$. Samples were vortexed and incubated at room temperature for 60 minutes in dark. Then protein was precipitated by adding $5 \mathrm{ml}$ of $20 \%$ TCA and centrifuged at $3000 \mathrm{rpm}$ for $10 \mathrm{~min}$, to collect protein precipitate, which was washed thrice with $4 \mathrm{ml}$ ofethyl acetate: ethanol (1:1) solution. Final protein precipitate was re-dissolved in 2 $\mathrm{ml}$ of $6 \mathrm{M}$ guanidine $\mathrm{HCl}$ in $20 \mathrm{mM}$ of potassium phosphate and kept at $37^{\circ} \mathrm{C}$ for $10 \mathrm{~min}$, and centrifuged to remove the insoluble substances and the absorbance was read at $372 \mathrm{~nm}$ against $2.5 \mathrm{M} \mathrm{HCl}$ blank. Known concentration of bovine serum albumin (BSA) dissolved in $6 \mathrm{M}$ guanidine $\mathrm{HCl}$ in $20 \mathrm{mM}$ of potassium phosphate was used as standard.

\section{Results and Discussion}

The rats of group 1 did not reveal any abnormal symptoms throughout the course of the experiment. Rats of group 2 showed pronounced depression, inappetance, loss of condition and also revealed reduction in feed, water consumption and weight gain. Two to three days after administration of the drug, marked polyuria and mild diarrhoea were observed in rats of group 2. Rats of group 4 also showed these symptoms, though they were mild to moderate when compared to group 2. Thorough postmortem was conducted on all sacrificed rats and lesions of pathological significance were recorded. Reduction in size of kidney was appreciable in rats of group 2 as compared to other groups (Fig.1).

The sections of kidney in group 2 on day 14 revealed moderate congestion (Fig.2) and marked inter tubular hemorrhages (Fig.3). Few sections revealed marked tubular dilatation (Fig.4). Sections on day 28 revealed moderate hemorrhages with disrupted tubular epithelium with few tubules showing moderate degenerative changes (Fig.5). Few glomeruli revealed disappearance of capillary network while few with shrunken glomeruli (Fig.6). The sections of kidney in group 4 on day 14 showed moderate tubular dilatation with mild degenerative changes (Fig.7) where as sections on day 28 showed mild dilatation of tubules (Fig.8). Transmission electron microscopy of kidney in 

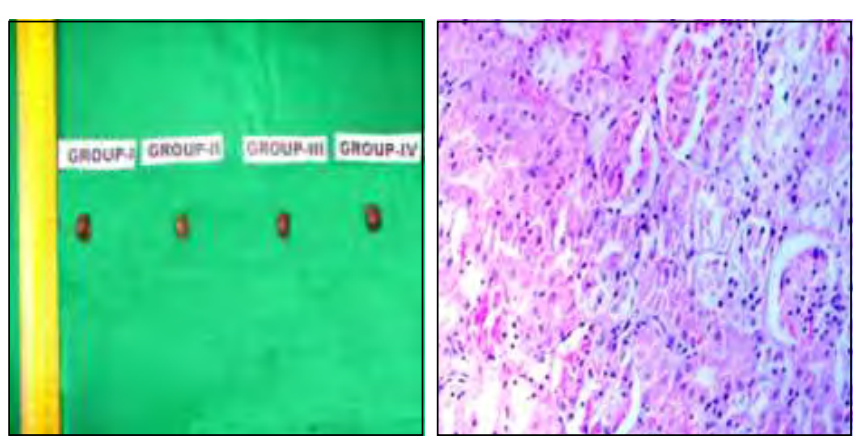

Fig. 1 Photograph of rat kidney II, day 28).
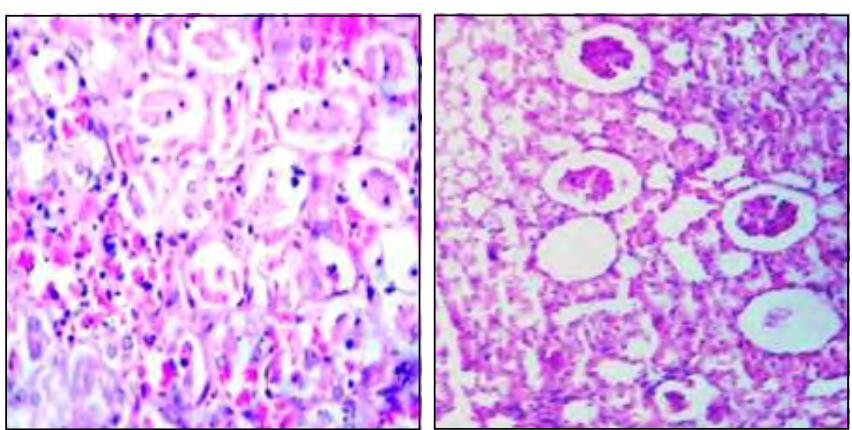

Fig. 5 Photomicrograph of Kidney Fig. 6. Photomicrograph of Kidney showing hemorrhages and showing shrunken glomeruli and disrupted tubular epithelium absence of capillary network in (Group2, day 28). H\&E $\times 100$
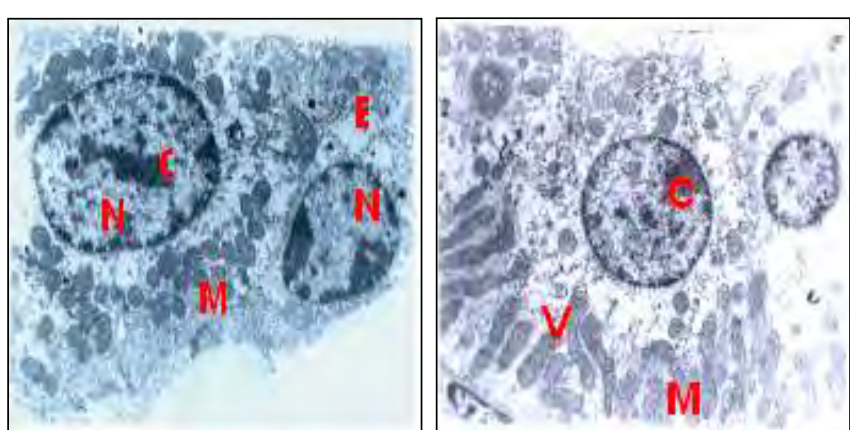

Fig. 9 TEM of kidney showing Fig. 10 TEM of kidney showing moderate dilation of tubules, nuclear changes like pyknosis, disruption of nuclear chromatin dilation of nuclear pores (NP) material (C), perinuclear clumping condensation, clumping of nuclear of mitochondria (M), margination material (C) and cell without of chromatin material and condensed nucleus (WN) (Group 2, day 28). 2, day 28). Uranyl acetate lead citrate $\times 8950$

group 2 revealed moderate dilatation of tubules, varied shapes and sizes of mitochondria, disruption of nuclear chromatin material, perinuclear clumping of mitochondria, marked cytoplasmic vacuolation, margination of chromatin material, disrupted and condensed endoplasmic reticulum (Fig.9). Few sections showed nuclear changes like pyknosis, dilatation of nuclear pores, condensation and clumping of nuclear material (Fig.10), degeneration of tubular epithelium, disruption of chromatin, elongation of mitochondria with electron dense granular material and cytoplasmic vacuolation (Fig.11), intact intercellular junction, pyknotic and swollen nucleus, varied shapes of mitochondria,condensed rough endopl-asmic reticulum and cytoplasmic vacuolation (Fig.12).
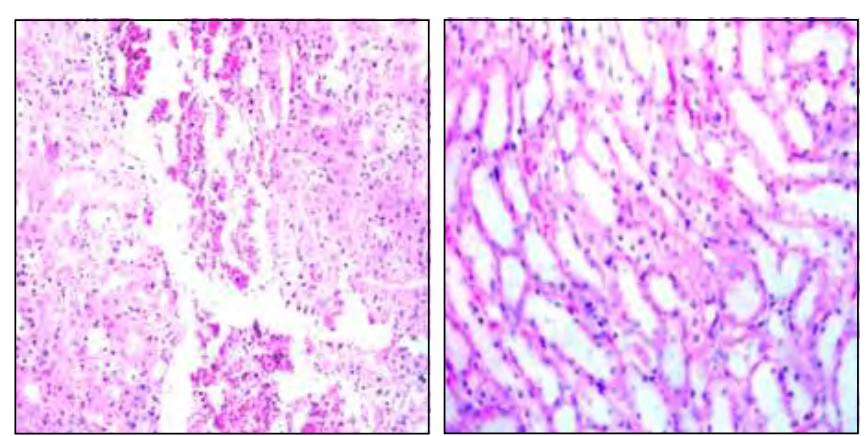

Fig. 3 Photomicrograph of kidney Fig. 4 Photomicrograph of kidney showing marked intertubular showing marked tubular dilation haemorrhages (Group 2, day 14) (Group 2, day 14). H\&E X100 $H \& E X 100$
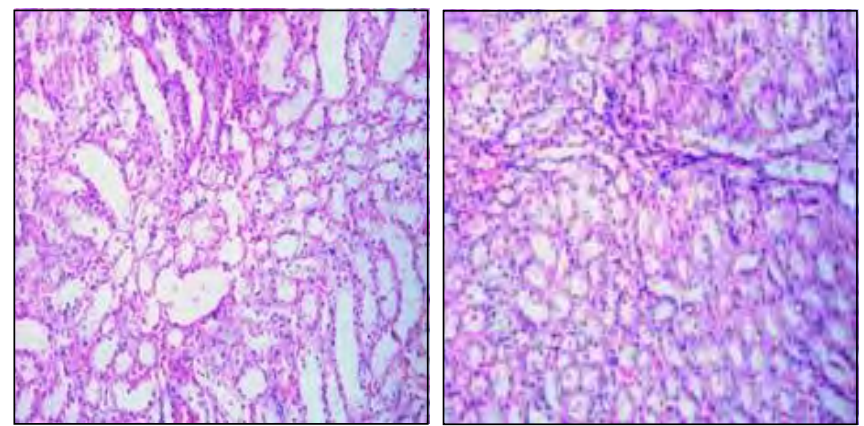

Fig. 7. Photomicrograph of Kidney Fig. 8 Photomicrograph of Kidney showing moderate tubular dilation showing mild dilation of tubules in and mild degenerative changes group 4 on day 28. H\&E X100 (Group 4, day 14). H\&E X 100
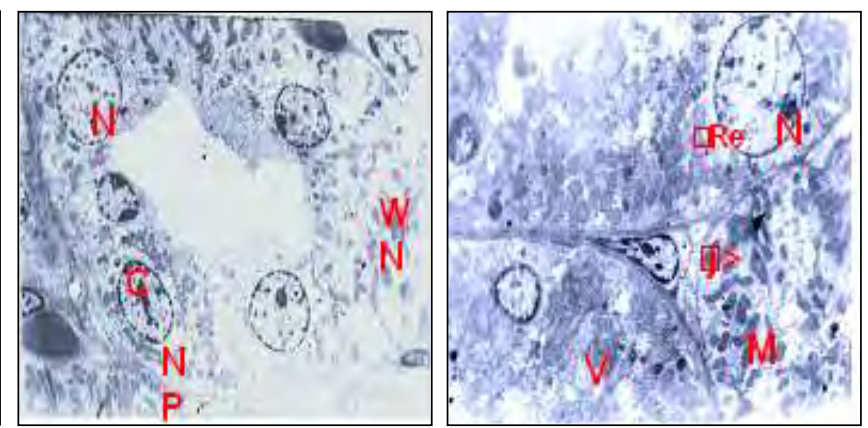

Fig. 11 TEM of kidney showing Fig. 12 TEM of Kidney showing loss of cell junction, degeneration intact intercellular junction (icj), of tubular epithelium, disruption pyknotic and swollen nucleus $(\mathrm{N})$, of chromatin (C), elongattion of varied shapes and sizes of mitochondria (M) with electron mitochondria (M), condensed dense granular material and rough endoplasmic reticulum cytoplasmic vacuolation (V) (RER) and cytoplasmic (Group 2, day 28). Uranyl acetate vacuolation (V) (Group 2, day 28). lead citrate X 6265 Uranyl acetate lead citrate $\times 3580$

Sections from rats of group 4 showed nucleus with uniform size, well differentiated nuclear membrane and nucleolus, intact inner and outer nuclear membrane (Fig.13). Few sections also revealed regenerating mitochondria and intact inter-tubular junction (Fig.14) and few sections with prominent inter tubular and inter cellular junctions, prominent nucleus, nucleolus and regenerating mitochondria (Fig.15). Certain others showed proximal convoluting tubules with regenerating brush border, swollen and elongated cilia and regenerating mitochondria (Fig.16).

The concentration of TBARS and protein carbonyls in rats of group 2 was significantly increased, whereas GSH concentration was significantly reduced compared to other groups. This might be due to accumulation of 

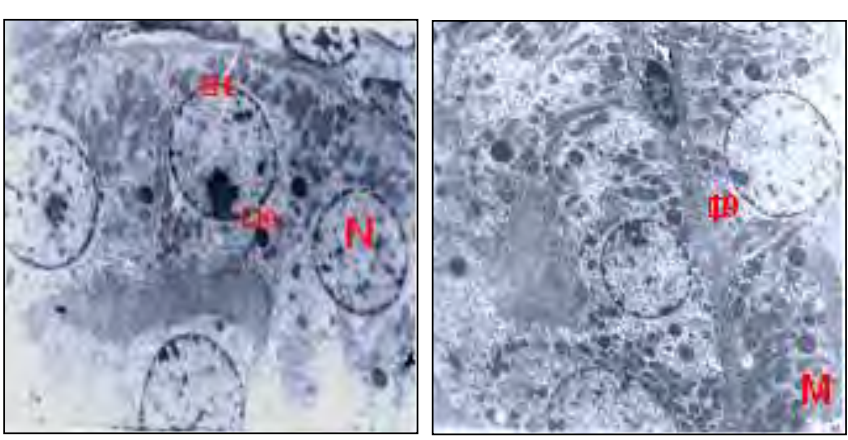

Fig. 13 TEM of kidney showing Fig. 14 TEM of kidney showing nucleus $(\mathrm{N})$ with uniform size, well regenenerating mitochondria $(\mathrm{M})$ differrentiated nuclear membrane and intact intertubular junction and outer nuclear membranes acetatelead citrate $\times 3580$ (NM) (Group 4, day 28). Uranyl acetate lead citrate $\times 4475$

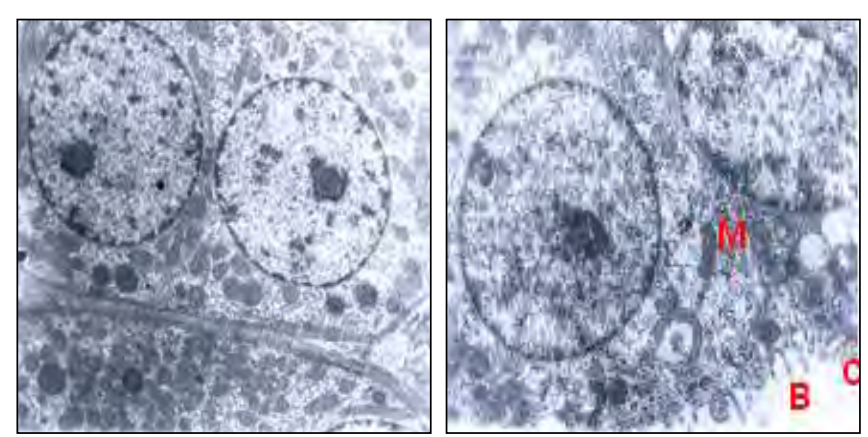

Fig. 15 TEM of kidney showing Fig. 16 TEM of kidney showing rominent inter tubular and inter proximal convoluting tubules with cellular junctions $(\mathrm{J})$, prominent regenerating brush border (B), nucleus (N), nucleolus (NL) and swollen, elongated cilia (C) and regenerating mitochondria (M) regenerating mitochondria (M). Uranyl acetate lead citrate X 6265 Uranyl acetate lead citrate X 8950

Table-1. Kidney biomarkers of oxidative stress indifferent groups of rats

\begin{tabular}{llll}
\hline Group & $\begin{array}{l}\text { TBARS } \\
\text { (n mol MDA/mg protein) }\end{array}$ & $\begin{array}{l}\text { Protein carbonyls } \\
\text { (n mol/mg protein) }\end{array}$ & $\begin{array}{l}\text { Reduced Glutatione } \\
\text { (n mol/mg protein) }\end{array}$ \\
\hline 1.Sham Control & $5.34 \pm 0.29^{\mathrm{a}}$ & $3.39 \pm 0.21^{\mathrm{a}}$ & $212.31 \pm 7.31^{\mathrm{a}}$ \\
2.Cisplatin & $11.47 \pm 0.72^{\mathrm{b}}$ & $9.42 \pm 0.48^{\mathrm{b}}$ & $96.70 \pm 5.36^{\mathrm{b}}$ \\
3.Turmeric & $4.92 \pm 0.22^{\mathrm{a}}$ & $3.11 \pm 0.26^{\mathrm{a}}$ & $210.66 \pm 8.40^{\mathrm{a}}$ \\
4.Cisplatin+Turmeric & $7.53 \pm 0.43^{\mathrm{c}}$ & $6.47 \pm 0.52^{\mathrm{c}}$ & $156.61 \pm 5.97^{\mathrm{c}}$ \\
\hline
\end{tabular}

Values are Mean \pm SE $(n=6)$; One way ANOVA (SPSS Version 15 )

Table-2. Serum biomarkers of nephrotoxicity in different groups of rats

\begin{tabular}{|c|c|c|c|c|}
\hline \multirow[t]{2}{*}{ Group } & \multicolumn{2}{|c|}{ BUN (mg/dl) } & \multicolumn{2}{|c|}{ Creatinine (mg/dl) } \\
\hline & Day 14 & Day 28 & Day 14 & Day 28 \\
\hline 1. Control & $14.36 \pm 0.75^{\mathrm{a}}$ & $14.26 \pm 0.93^{\mathrm{a}}$ & $1.36 \pm 0.18^{\mathrm{a}}$ & $1.31 \pm 0.12^{\mathrm{a}}$ \\
\hline 2.Cisplatin & $28.49 \pm 2.13^{b}$ & $34.05 \pm 2.39^{b}$ & $3.63 \pm 0.21^{b}$ & $6.57 \pm 0.38^{b}$ \\
\hline 3.Turmeric & $13.45 \pm 1.16^{a}$ & $13.73 \pm 1.26^{a}$ & $1.35 \pm 0.16^{a}$ & $1.18 \pm 0.17^{a}$ \\
\hline 4.Cisplatin +Turmeric & $20.40 \pm 1.00^{c}$ & $24.37 \pm 2.15^{c}$ & $2.42 \pm 0.23^{c}$ & $4.27 \pm 0.29^{c}$ \\
\hline
\end{tabular}

Values are Mean \pm SE $(n=6)$; One way ANOVA (SPSS Version 15)

Values with different superscripts differ significantly $(P<0.05)$ in the same column

cisplatin in renal epithelial cells' mitochondria, which further enhanced Reactive Oxygen Species (ROS) generation by reduced activity of antioxidant enzymes and by depleting GSH levels. These findings are in accordance with the results described previously in rats $[19,20]$. Further, it might be due to the oxidation of mitochondrial proteins and lipids that caused increase in protein carbonyls and TBARS, which was indicated by increased levels of renal biomarkers (creatinine and BUN) in serum. These findings are in agreement withearlier reports [21].

Histological sections of kidney in group 2 showed tubular dilatation, shrunken glomerulus, hyaline casts, inter tubular congestion and other degenerative changes. Transmission electron microscopy (TEM) revealed dense chromatin in nucleus and mitochondrial changes. As kidney being essential organ of metabolism and elimination of toxic components, besides rich in poly unsaturated fatty acids that are the targets for electrophilic molecules, it served as a major site of attack for cisplatin that gets activated to reactive platinum complex in vivo. Accumulation of reactive metabolites of cisplatin induces alterations in cellular level that might be due to induction of reactive oxygen species and subsequent oxidative damage. These findings are in accordance with the earlier findings of
Prathibha et al. and Chattopadhyay et al.[22, 23] .

\section{Conclusion}

There was improvement in group 4 (Cisplatin + turmeric) in all parameters compared to group 2 (Cisplatin alone), as turmeric had antioxidant properties through which it combats ROS which was confirmed by the results of the study.

\section{Authors' contributions}

The present article was part of BR's M.V.Sc research work. YA designed and approved the experimental protocol. PS drafted the manuscript and AGR critically reviewed the manuscript and provided laboratory animal facilities, DM was the minor research supervisor who made critical suggestions in conducting the experiment, ML was the incharge of Ruska Labs where electron microscopy of the samples was done. All authors read and approved the final manuscript.

\section{Acknowledgements}

The authors are thankful to the Sri Venkateswara Veterinary University, Tirupati for funding the research. 


\section{Competing interests}

The authors declare that they have no competing interests.

\section{References}

1. Nanda Kumar, A. (1990-1996) National Cancer Registry Program, Indian Council of Medical Research, Consolidated Report of Population Based Cancer Registries, New Delhi, India.

2. Stephen, T. (2005) Cisplatin. Chemical and Engineering News 83: 52

3. Noori, S. and Mahboob, T. (2010). Protective role of carnosine pretreatment on cisplatin- induced kidney damage in rats. Indian Journal of Clinical Biochemistry 25: 86-91.

4. Pratibha, R., Sameer, R., Padmanabh, V., Rataboli., Dayanand, A., Bhiwgade. and Chitra, Y. D. (2006) Enzyme studies of cisplatin induced hepatic tissue damage in rats. European Journal of Pharmacology 532:290-293.

5. Naqshbandi, A., Khan, M. W., Rizwan, S., Yusufi, A. N. K. and Khan, F. (2011) Protective role of fish oil in cisplatin induced liver toxicity.Biology and Medicine 3:86-97.

6. Zafar, A. B. R., David, B. and Pradip, D. (2010) Prevention of Cisplatin Induced Nephrotoxicity by Ethanolic Extract of Embelia ribes Fruits and $\alpha$ Tocopherol in Experimental Animals. Journal of Complementary and Integrative Medicine 7:53.

7. Sudhavani, V., Chinnikrishnaiah, V., Raghu, Moorthy, V., Raghavendra, H.G. and Ranganayakulu, D. (2010) Merremiaemarginata burmprotects against cisplatin induced nephrotoxicity rats. Journal of Advances in Drug Research 1: 2230-7761.

8. Ulkan, K., Ertugrul, K., Zeynep, T., Mehmet, T., Ibrahim H. O., Okkes, Y., Fikrettin, S., and Kazim, S.(2013) Melatonin suppresses cisplatin-induced nephrotoxicity via activation of Nrf-2/HO-1 pathway.Nutrition \& Metabolism 10:7.

9. Zsuzsanna, K.,Zsengeller,L. E., Dan, B., Bela, H., Partha, M. B. K., Samir M. P., Ananth. K., Isaac E. S., Pal, P. (2012) Cisplatin Nephrotoxicity Involves Mitochondrial Injury with Impaired Tubular Mitochondrial Enzyme Activity. Journal of Histochemistryand Cytochemistry 60: 521-529.

10. Deeb, D., Xu, Y. X., Jiang, H., Gao, X., Janakiram, N., Chapman, R. A. and Gautam, S. C. (2003) Curcumin enhances TNF-related apoptosis enhancing ligand-induced apoptosis in LNCaPprostate cancer cells. Molecular Cancer Therapeutics 2: 95-103.

11. Ramya, B., Anjaneyulu,Y.,Gopalareddy, A.(2013)A study on cisplatin-induced hepatotoxicity and protectiverole of turmeric in rats. International Journal of Pharma and Bio Sciences 4(1): (b) 133-143.

12. Snedecor, G. W. and Cochran, W. G. (1994) Statistical methods, 8th edition, IOWA State University Press, Amer, IOWA, USA. Pp. 237-252.

13. Satia, N. C., Dawani, R. R. and Goyal, R. K. (1997)Benefical effects of clonidine in streptozocine induced Diabetes and Doca-hypersensitive rats. Journal of Pharmacy and Pharmacology 49:1030-1035.

14. Culling C F A,Handbook of Histopathological Technique, (Butterworth \& Company (Publishers) Limited Landon) 1957. Pp. 1-50.

15. Bozzola, J. J. and Russell, L. D. 1999. Electron Microscopy: Principles and Techniques for Biologists. $2^{\text {nd }}$ Edn., Jones and Bartlett, Boston.

16. Moron, M. S., Depierre, J. W. and Mannervik, B. (1979) Levels of GSH, glutathione reductase and GST in rat lung and liver. Biochimica et Biophysica Acta. 582: 67-68.

17. Balasubramanian, K. A., Manohar, M. and Mathan, V. I. (1988)An unidentified inhibitor of lipid peroxidation in intestinal mucosa. Biochimicaet Biophysica Acta. 962:5158.

18. Levine, R. L., Garland, D., Oliver, C. N., Amici, A., Climent, I., Lenz, A, G., Ahn, B, W., Shaltiel, S. and Stadtman, E. R. (1990) Determination of carbonyl concentration in oxidative proteins. Methods in Enzymology. 186: 464-478.

19. Yousef, M. I., Saad, A. A. and El-Shennawy, L. K. (2009) Role of grape seedextract in by cisplatininduced oxidative damagein rats. Food and Chemical Toxicology 47: 1176 1183.

20. Marie, H. H. and Prasad, D. (2003) Molecular mechanisms inCisplatin renal-toxicity.Cancer Therapeutics. 1: 47-61.

21. Santos, N. A., Catao, C. S., Martins, N. M., Curti, C., Bianchi, M.L. and Santos, A.C. (2007)Cisplatin induced nephrotoxicity is associated with redox state imbalance, impairedenergy metabolism and apoptosis in rat kidney mitochondria. Archieves of Toxicology. 81:495-504.

22. Pratibha, R., Dayanand, A., Bhiwgade., Sameer, K., Padmanabh, V., Rataboli. And Chitra, Y. D. (2010) Cisplatin induced histological changes in renal tissue of rat. Journal of Cell and Animal Biology.4: 108-111.

23. Chattopadhyay, I., Kaushik, B., Bandyopadhyay, U. and Banerjee, R.K. (2004) Biological effects and medicinal properties of turmeric and curcumin, Current Science, 87 :4453. 